LAWRENCE LIVERMORE N A T IO N A L LABORATORY

Comparison of Average Transport and Dispersion Among a Gaussian Model, a Two-Dimensional Model and a Three-Dimensional Model

J. A. Mitchell, C. R. Molenkamp, N. E. Bixler, C. W. Morrow, J. V. Ramsdell, Jr.

May 13, 2004

International Conference on Probablistic Safety Assessment and Management 7

Berlin, Germany

June 14, 2004 through June 18, 2004 
This document was prepared as an account of work sponsored by an agency of the United States Government. Neither the United States Government nor the University of California nor any of their employees, makes any warranty, express or implied, or assumes any legal liability or responsibility for the accuracy, completeness, or usefulness of any information, apparatus, product, or process disclosed, or represents that its use would not infringe privately owned rights. Reference herein to any specific commercial product, process, or service by trade name, trademark, manufacturer, or otherwise, does not necessarily constitute or imply its endorsement, recommendation, or favoring by the United States Government or the University of California. The views and opinions of authors expressed herein do not necessarily state or reflect those of the United States Government or the University of California, and shall not be used for advertising or product endorsement purposes. 


\title{
Comparison of Average Transport and Dispersion Among a Gaussian Model, a Two-Dimensional Model and a Three- Dimensional Model
}

\author{
J.A. Mitchell \\ U.S. Nuclear Regulatory Commission \\ Washington, D.C., USA \\ Charles Molenkamp \\ Lawrence Livermore National Laboratory \\ Livermore, CA, USA \\ Nathan E. Bixler, Charles W. Morrow \\ Sandia National Laboratories \\ Albuquerque, NM, USA \\ James V. Ramsdell, Jr. \\ Pacific Northwest National Laboratories \\ Richland, WA, USA
}

\begin{abstract}
The Nuclear Regulatory Commission uses MACCS2[1] (MELCOR Accident Consequence Code System, Version 2) for regulatory purposes such as planning for emergencies and cost-benefit analyses. MACCS2 uses a straight-line Gaussian model for atmospheric transport and dispersion. This model has been criticized as being overly simplistic, although only expected values of metrics of interest are used in the regulatory arena. To test the assumption that averaging numerous weather results adequately compensates for the loss of structure in the meteorology that occurs away from the point of release, average MACCS2 results have been compared with average results from a state-of-the-art, 3-dimensional LODI[2] (Lagrangian Operational Dispersion Integrator)/ADAPT[3] (Atmospheric Data Assimilation and Parameterization Technique) and a Lagrangian trajectory, Gaussian puff transport and dispersion model from RASCAL[4] (Radiological Assessment System for consequence Analysis). The weather sample included 610 weather trials representing conditions for a hypothetical release at the Central Facility of the Department of Energy's Atmospheric Radiation Measurement site. The values compared were average ground concentrations and average surface-level air concentrations at several distances out to 100 miles $(160.9 \mathrm{~km})$ from the assumed release site.
\end{abstract}

\section{Background}

The Nuclear Regulatory Commission's code for predicting off-site consequences, MACCS2[1] (MELCOR Accident Consequence Code System, Version 2), uses a simplified model for atmospheric transport and dispersion (ATD), that is, a straight-line Gaussian model. This model has been criticized as being overly simplistic, even for its purpose. The justification for its use has been that only average or expected values of metrics of interest are needed for planning and that a simplified model, by averaging metrics of interest obtained using numerous weather sequences one-by-one, compensates for the loss of structure in the meteorology that occurs away from the point of release. The simple model has been retained because of the desire to have short running times on personal computers covering the entire path through the environment, including the food and water pathway, and covering essentially a lifetime of exposure to a contaminated environment.

The assumption about the adequacy of averaging metrics of interest over numerous weather sequences has never been tested for the Nuclear Regulatory Commission's (NRC's) purposes. Because of an increased interest in Level-3 Probabilistic Risk Assessments (PRAs), testing of the assumption has been performed. 
The results from MACCS2, the simplified model; LODI[2] (Lagrangian Operational Dispersion Integrator), a state-of-the-art, 3-dimensional advection-diffusion code using a Lagrangian stochastic, Monte Carlo method. RASCAL[4] (Radiological Assessment System for consequence analysis), which uses a Lagrangian trajectory, Gaussian puff model, have been compared. RASCAL is between MACCS2 and LODI in complexity. LODI is coupled to ADAPT[3] (Atmospheric Data Assimilation and Parameterization Technique), which provides fields of mean winds, turbulence, pressure, temperature, and precipitation based on observed or model-simulated meteorology. RASCAL uses meteorological fields generated by interpolation of surface data.

The objective of this study is to see if the average ATD results from these three codes are sufficiently close that a more complex model is not required for the NRC purposes of planning and cost-benefit analysis or different enough that the NRC code should be modified to provide more rigorous ATD. The decision will be made by the NRC using the results of this study and other factors. It would be best if MACCS2 results could be compared with measurements over the long distances and types of terrain of interest to the NRC. However, such measurements do not exist, so the less desirable comparison with a state-of-the-art code was chosen to provide input into the decision on the adequacy of the MACCS2 ATD. Comparisons of LODI/ADAPT results with intentional and unintentional releases can be found in Foster, et al[5]. These comparisons, although over shorter ranges than those of interest to the NRC, show that excellent results can be obtained and that LODI/ADAPT is sufficiently accurate for the purposes of this study.

\section{MACCS2}

MACCS2 is the latest in a series of NRC-sponsored codes for estimating off-site consequences following a release of radioactive material into the environment. The first code in the series was CRAC (Calculation of Reactor Accident Consequences), which was developed for the Reactor Safety Study[6]. MACCS2 is a versatile code, with most of the parameters being under user control to facilitate the performance of sensitivity and uncertainty analyses. The principal phenomena considered by MACCS2 are: atmospheric transport, short- and long-term mitigative actions and exposure pathways, deterministic and stochastic health effects, and economic costs. Of these capabilities, only the atmospheric processes have been considered in the present study.

The normal calculation mode for MACCS2 is to sample various weather sequences (wind speed and direction, stability class, and accumulated precipitation representing a single spatial point) and to calculate ATD using a straight-line Gaussian model in each of 16 directions; each direction is 22.5 degrees wide and centered on a compass point. Each sequence is weighted by its probability of occurrence. The weather sequences are normally chosen, and have been chosen for this study, to emphasize sampling of sequences believed to be of importance to the prediction of early health effects in an exposed population. Sixteen (weighted) values of metrics of interest are available for each weather sequence, which are used to produce a mean value for that sequence. The mean values that are of interest for planning and cost-benefit analyses are constructed from the (weighted) sequence values.

\section{LODI/ADAPT}

LODI solves the 3-dimensional advection-diffusion equation using a Lagrangian stochastic, Monte Carlo method. It is coupled to ADAPT (Atmospheric Data Assimilation and Parameterization Technique), which uses modern data assimilation techniques to provide mass-consistent winds and turbulence fields bases on observed meteorological parameters and/or regional model simulated data. Further, both codes are coupled to a database of topographical and geographical information, which has been used to describe the area of interest. For this study, we used hourly average wind and turbulence fields for each of the 610 release sequences. One value of each of the chosen metrics is available for each weather sequence.

\section{RASCAL}


RASCAL contains a Lagrangian trajectory, Gaussian puff atmospheric dispersion model. Surface meteorological data are used to create the time-varying fields (wind, stability, and precipitation) used by the model.

\section{Weather Data and Sequences ${ }^{1}$}

The location chosen for the present study is Southern Great Plains site of the Department of Energy's Atmospheric Radiation Measurement (ARM) Program in Oklahoma and Kansas. Meteorological data were acquired from the ARM data archive for all of the year 2000. This included surface and upper air meteorological measurements from the ARM, the National Oceanic and Atmospheric Administration (NOAA), and the Oklahoma mesonet[7]. The mesonet's web site describes it as a "world-class network of environmental monitoring stations," with at least one station in each of Oklahoma's 77 counties. The stations, which were designed and implemented by scientists from Oklahoma University and Oklahoma State University, transmit data from 10-meter tall towers in near-real time. The network was designed to measure the environment "at the size and duration of mesoscale weather events." The release was assumed to occur at the Central Facility of the Department of Energy's ARM site, near Lamont, OK (36.605N, 97.485W).

MACCS2 uses as its weather input 8760 records, representing each hour of 365 days, containing: the direction toward which the wind is blowing, the wind speed, the Pasquill stability class, and the accumulated precipitation. The stability class was estimated by a turbulence-based method, which uses the standard deviation of the wind direction in combination with the scalar mean wind speed. MACCS2 uses hour-after-hour data from the start time of the release until the plume progresses to the end of the computational mesh. For start times in December where there are not enough hours in the year to complete the translation of the plume to the end of the domain, hours in January are used. The ARM Central Facility data for 2000 had only a few gaps, representing less than $0.1 \%$ of the hours. Where gaps existed, the observations from nearby towers (Ashton, OK; Towanda, KS) were used.

ADAPT uses meteorology data from multiple sites to construct fields of mean winds, turbulence, pressure, temperature, and precipitation for use by LODI. LODI does not "wrap-around" for start times in December as does MACCS2. However, 2000 was a leap year, providing an additional 24 hours of data to allow translation of the plume through the entire computational mesh. The Oklahoma mesonet and ARM surface $(10 \mathrm{~m})$ and upper air (up to $6 \mathrm{~km}$ ) data were processed into observation input files for ADAPT. The upper air data included that from balloon sondes, from radar wind profiler (RWP)/ Radio Acoustic Sounding System (RASS), from Atmospheric Emitted Radiance Interferometers (AERI), and from the RWP/RASS system operated by the National Oceanic and Atmospheric Administration's Wind Profiler Demonstration Network.

All three codes need a mixing height. ADAPT and RASCAL use hourly values, while MACCS2 uses seasonal values, a morning and an afternoon value for each season. The MACCS2 mixing heights for the ARM site were an average over the appropriate hourly and seasonal data. For ADAPT, the Heffter method[8] was used for the hourly estimates based on sonde and profiler measurements, that is, the mixing height was estimated as the lowest height where a continuous stable layer produced a $2^{\circ} \mathrm{C}$ increase in potential temperature. Central Facility and four boundary sites were used and the estimated mixing heights were subsequently averaged to provide a domain value. Gaps in the data for these values represented less than $3 \%$ of the hours. Where gaps existed, cloud base heights from the AERI data or, as a last resort for less than $0.1 \%$ of the hours, judgment based on previous or subsequent hours. Hourly mixing heights for RASCAL were estimated from surface winds and stability using methods based on relationships derived by Zilitinkevich[9].

\footnotetext{
${ }^{1}$ Data were obtained from the Atmospheric Radiation Measurement (ARM) Program sponsored by the U.S. Department of Energy, Office of Science, Office of Biological and Environmental Research, Environmental Sciences Division, and from the Oklahoma Mesonet, Oklahoma Climate Survey, University of Oklahoma.
} 
Six hundred ten weather sequences were chosen, including various stability classes, wind speeds, and rain conditions. The specific start times for the sequences were chosen based on MACCS2's option for stratified random sampling of weather "bins." In this option, each of the 8760 hours was placed into one of 16 fixed bins, which depend on stability class and wind speed and, for this study, additional rain bins, which depend on distance from the release point and rain accumulated during the hour. Note that for any given meteorology file, some bins defined in this fashion may be empty. MACCS2 allows the user to choose different numbers of weather sequences from each bin, and this feature has been used in this study. Either $5 \%$ of the number of weather sequences in each bin or 12 start times from a bin, whichever was larger, was used, yielding the 610 values for use by all three codes.

ADAPT has access to files of orographic features and this file was used in the calculation of the 3dimensional wind field for the computational domain. However, the topography and land use in the Southern Great Plains ARM site are relatively unfeatured; there is a general down slope from NW to SE, some river valleys, and some forested areas in the Eastern part of the domain.

Notwithstanding this uniform topography and land use, the ARM site was chosen because of the vast quantity of high quality meteorological data available. Other locations that have more variable features do not have the coverage of observations.

\section{Computational Domain}

It is known that comparisons of a single predicted concentration to its corresponding measured concentration are likely to be many orders of magnitude different, even when the plume is predicted to go in the correct direction[10]. On the other hand, the referenced study also showed that the average of the predictions was within a factor of two of the average of the measurements for several different models. However, the distances over which these comparisons were made are small in comparison with the distances over which the MACCS2 calculations are typically performed $(1000$ miles, $1609 \mathrm{~km})$. The present study extends the distance over which the comparison is made to 100 miles $(160.9 \mathrm{~km})$ from the assumed release. It would have been desirable to extend the ATD comparison over an even larger distance from the release point, but the availability of high-quality archived data, the processing time for that data, and the code run-time for the 610 weather sequences made the distance of 100 miles $(160.9 \mathrm{~km})$ the practical limit. This limit will still provide input to the NRC's decision about MACCS2's ATD adequacy because it is a distance within which the majority of the health and economic effects of large releases from nuclear power plants are expected. Further, if the ATD at this distance is deemed to be adequate for the NRC's purposes, it will be adequate for any smaller distance.

MACCS2 uses a polar coordinate system, while LODI/ADAPT and RASCAL use Cartesian coordinates. MACCS2 normally edits measures of interest over radial rings but, for this study, a special capability was added to edit additionally by the 16 compass directions. In order to compare LODI results for its Lagrangian particles, a special capability was added to average those particles that ended up in areas defined by the radial distances and directional lines. The specific distances chosen for comparison were: 9 to 10,19 to 20,49 to 50 , and 99 to 100 miles (14.5 to $16.1,30.6$ to $32.2,78.8$ to 80.5 , and 159.3 to 160.9 $\mathrm{km})$. The RASCAL domain is limited to a maximum of $100 \mathrm{mi}(161 \mathrm{~km})$ on a side. Consequently, RASCAL results are limited to the first three distances. In order to have the influence of additional area beyond the range of interest during development of the 3-dimensional wind field, the LODI/ADAPT domain was 248.5 miles $(400 \mathrm{~km})$ on a side.

\section{Other Important Parameters}

\section{Source Term}

The study was not designed to represent a realistic release from a real facility. The assumed release was uniform over $1800 \mathrm{sec}$ and contained $2.7 \times 10^{5} \mathrm{Ci}\left(10^{16} \mathrm{~Bq}\right)$ of each of a long-lived non-depositing and a long-lived depositing material. The release was further assumed to take place $164 \mathrm{ft}(50 \mathrm{~m})$ above the ground and to contain $3 \times 10^{6}$ watts of buoyant energy. In order to approximate a point source, the initial 
plume size parameters were $3.28 \mathrm{ft}(1 \mathrm{~m})$ for both $\sigma_{\mathrm{y}}$ and $\sigma_{\mathrm{z}}$. The choice of the radioactive material content is not important in the context of this study, since the results presented below scale directly with the release magnitude. The size of the release just needs to be large enough to provide enough material to travel to the end of the computational domain. The situation for an actual release from a facility (especially a nuclear power plant) would be more complex and would not directly scale, since many radionuclides (having short, medium, and long half-lives) would be released.

\section{Deposition Velocities}

Dry deposition for particulate material (in this case, cesium) is calculated in MACCS2 and RASCAL by the source depletion method, using the simplifying assumption that deposition onto the ground does not affect the vertical distribution of the material. The concentration of material at any single point on the ground is the product of the integrated ground-level air concentration times the deposition velocity. Only one particle size was assumed for the depositing material and a dry deposition velocity of $0.39 \mathrm{in} / \mathrm{sec}(1 \mathrm{~cm} / \mathrm{sec})$ was assigned. MACCS2 calculations for nuclear power plant accidents normally use comparable values. For LODI, dry deposition is a function of the gravitational settling velocity and the deposition resistance, although in this case we assigned a small particle size so deposition was due solely to deposition resistance to correspond to the MACCS2 method. As in MACCS2 and RASCAL, particles are removed from the surface layer.

MACCS2's wet deposition model considers washout, that is, collection of particulate material by falling drops. Since washout is a very efficient process, the neglect of rainout (collection of particulate material by drops in clouds) is not important. The model depends on both the rain duration and the rain intensity. The fraction remaining airborne is: $\exp \left(\mathrm{a} \bullet(\right.$ rain duration $\left.) \bullet(\text { rain intensity })^{\mathrm{b}}\right)$. For this study, $\mathrm{b}$ was chosen as 0.75 and a as $0.7 \times 10^{-4} / \mathrm{sec}$, the latter corresponding roughly to a value for light rain. The rain intensity is important, since washout is an interception process where a kernel describes the attachment rate for the particle size distribution of particulate material and the particle size distribution of raindrops. LODI normally models this process with a scavenging coefficient that is a function of precipitation rate and particle size distribution of the particulate material, but for this study the scavenging rate was specified as described above for MACCS2. RASCAL models wet deposition using a washout model with washout coefficients that are coarse functions of the precipitation rate (light, moderate, or heavy) and type (rain or snow). For light rain, the RASCAL washout coefficient is about $2 \times 10^{-4} / \mathrm{sec}$.

\section{Metrics of Interest}

The metrics of interest for this study have been chosen to compare only ATD-related phenomena. Although the codes contain health effects models, comparison of those metrics would have introduced a complication in ensuring exact compatibility of dose conversion factors. Therefore, the metrics did not include those for which dose conversion factors or health effect factors are used. Ground contamination and airborne concentrations integrated over the entire plume passage at the distances discussed above and for the 16 compass directions were chosen. The comparison is of the averages of these metrics over the 610 weather sequences.

\section{Results}

Table 1 contains the results for the four distances for the three metrics used in this study, averaged over the 610 chosen weather sequences. Only the averages over rings around the release site are presented here. This study will be one of the factors considered by the Nuclear Regulatory Commission in its decision either to retain the present MACCS2 ATD model or a decision to improve the MACCS2 ATD model. The decision will be made as part of a larger review of the future of MACCS2, early in 2004.

\section{References}


1. Chanin, D., Young, M.L., Randall, J., "Code Manual for MACCS2,” NUREC/CR-6613, May 1998.

2. Leone, J.M., Nasstrom, J.S., Maddix, D.M., Larsen, D.J., and Sugiyama, G., “2001: LODI User's Guide, Version 1.0," Lawrence Livermore National Laboratory, Livermore, CA.

3. Sugiyama, G. and Chan, SS.T., "A New Meteorological Data Assimilation Model for Real-Time Emergency Response," $10^{\text {th }}$ Joint Conference on the Applications of Air Polution Meteorology,

Phoenix, AZ, 1998.

4. Sjoreen, A.L. Ramsdell, J.V., Jr., McKenna, T.J., McGuire, S.A., Fosmire, C., and Athey, G.F., "RASCAL 3.0: Description of Models and Methods," NUREG-1741, March 2001.

5. Foster, K.T., Sugiyama, G. Nasstrom, J.S. Leone, Jr., J.M., Chan, S.T., and Bowen, B.M., "The Use of an Operational Model Evaluation System for Model Intercomparison, “ International Journal of Environment and Polution, Vol. 14, 2000.

6. "Reactor Safety Study: Calculation of Reactor Accident Consequences," WASH-1400, NUREG 75/014, Appendix 6, Nuclear Regulatory Commission, Washington, DC.

7. http://okmesonet.ocs.ou.edu/

8. Heffter, J.L., "Transport Layer Depth Calculation, Second Joint Conference on Applications of Air Pollution Meteorology, New Orleans, LA, 1980.

9. Zilitinkevich, S.S., "On the Determination of the Height of the Ekman Boundary Layer," Boundary-Layer Meteorology, Vol. 3, No. 2, pp. 141-145.

10. Draxler, R.R., "Accuracy of Various Diffusion and Stability Schemes Over Washington, D.C.," Atmospheric Environment, Vol. 21, No. 3, pp. 491, 499.

Table 1

Results of Atmospheric Transport and Dispersion MACCS2, RASCAL, LODI/ADAPT

\begin{tabular}{|c|c|c|c|}
\hline Metric & MACCS2 & RASCAL & LODI/ADAPT \\
\hline $\begin{array}{l}\text { 9-10 mi depositing } \\
\text { material } \mathrm{Bq} / \mathrm{m}^{2}\end{array}$ & $6.3 \times 10^{5}$ & $7.2 \times 10^{5}$ & $4.7 \times 10^{5}$ \\
\hline $\begin{array}{l}\text { 19-20 mi depositing } \\
\text { material } \mathrm{Bq} / \mathrm{m}^{2}\end{array}$ & $1.7 \times 10^{5}$ & $2.3 \times 10^{5}$ & $1.6 \times 10^{5}$ \\
\hline $\begin{array}{l}\text { 49-50 mi depositing } \\
\text { material } \mathrm{Bq} / \mathrm{m}^{2}\end{array}$ & $3.0 \times 10^{4}$ & $4.7 \times 10^{4}$ & $3.5 \times 10^{4}$ \\
\hline $\begin{array}{l}\text { 99-100 mi depositing } \\
\text { material } \mathrm{Bq} / \mathrm{m}^{2}\end{array}$ & $9.2 \times 10^{3}$ & Not calculated & $9.9 \times 10^{3}$ \\
\hline $\begin{array}{l}\text { 9-10 mi depositing } \\
\text { material Bq Sec/m } 3\end{array}$ & $5.9 \times 10^{7}$ & $5.9 \times 10^{7}$ & $3.7 \times 10^{7}$ \\
\hline $\begin{array}{l}\text { 19-20 mi depositing } \\
\text { material } \mathrm{Bq} \mathrm{Sec} / \mathrm{m}^{3}\end{array}$ & $1.5 \times 10^{7}$ & $2.0 \times 10^{7}$ & $1.3 \times 10^{7}$ \\
\hline $\begin{array}{l}\text { 49-50 mi depositing } \\
\text { material Bq Sec/m } \mathrm{m}^{3}\end{array}$ & $2.6 \times 10^{6}$ & $3.9 \times 10^{6}$ & $2.9 \times 10^{6}$ \\
\hline $\begin{array}{l}\text { 99-100 mi depositing } \\
\text { material Bq Sec } / \mathrm{m}^{3}\end{array}$ & $8.0 \times 10^{5}$ & Not calculated & $8.2 \times 10^{5}$ \\
\hline $\begin{array}{l}\text { 9-10 mi non-depositing } \\
\text { material } \mathrm{Bq} \mathrm{Sec} / \mathrm{m}^{3}\end{array}$ & $9.4 \times 10^{7}$ & $7.3 \times 10^{7}$ & $5.1 \times 10^{7}$ \\
\hline $\begin{array}{l}\text { 19-20 mi non-depositing } \\
\text { material } \mathrm{Bq} \mathrm{Sec} / \mathrm{m}^{3}\end{array}$ & $2.7 \times 10^{7}$ & $3.1 \times 10^{7}$ & $2.3 \times 10^{7}$ \\
\hline $\begin{array}{l}\text { 49-50 mi non-depositing } \\
\text { material } \mathrm{Bq} \mathrm{Sec} / \mathrm{m}^{3}\end{array}$ & $5.1 \times 10^{6}$ & $8.4 \times 10^{6}$ & $6.9 \times 10^{6}$ \\
\hline $\begin{array}{c}99-100 \text { mi non- } \\
\text { depositing material Bq } \\
\mathrm{Sec} / \mathrm{m}^{3}\end{array}$ & $1.8 \times 10^{6}$ & Not calculated & $2.5 \times 10^{6}$ \\
\hline
\end{tabular}

